\title{
Short-term rosuvastatin therapy prevents contrast-induced acute kidney injury in female patients with diabetes and chronic kidney disease: a subgroup analysis of the TRACK-D study
}

\author{
Jing $\mathrm{Li}^{1}$, Yi Li ${ }^{1}$, Biao Xu${ }^{2}$, Guoliang Jia ${ }^{3}$, Tao Guo ${ }^{4}$, Dongmei Wang ${ }^{5}$, Kai Xu' ${ }^{1}$, Jie Deng ${ }^{1}$, Yaling Han $^{1}$ \\ ${ }^{1}$ Department of Cardiology, General Hospital of Shenyang Military Region, Shenyang 110016, China; ${ }^{2}$ Nanjing Drum Tower Hospital Tower Hospital, \\ the Affiliated Hospital of Nanjing University Medical School, Nanjing 210029, China; ${ }^{3}$ Dongguan Kanghua Hospital, Dongguan 523080, China; ${ }^{4}$ First \\ Affiliated Hospital of Kunming Medical University, Kunming 650031, China; ${ }^{5}$ Shijiazhuang Peace Hospital, Shijiazhuang 050081, China \\ Contributions: (I) Conception and design: Y Han; (II) Administrative support: Y Han, J Li; (III) Provision of study materials or patients: Y Han, B \\ Xu, G Jia, T Guo, D Wang; (IV) Collection and assembly of data: J Li, Y Li, K Xu, J Deng; (V) Data analysis and interpretation: J Li, Y Li; (VI) \\ Manuscript writing: All authors; (VII) Final approval of manuscript: All authors. \\ Correspondence to: Dr. Yaling Han, MD, FACC. Department of Cardiology, General Hospital of Shenyang Military Region, 83 Wenhua Road, \\ Shenyang 110016, China. Email: hanyaling@263.net.
}

\begin{abstract}
Background: Female patients are at higher risk of contrast-induced acute kidney injury (CIAKI) compared to males. In the multicenter, prospective, TRACK-D study, short-term rosuvastatin has proven effectively reduce CIAKI in patients with type 2 diabetes mellitus and stage 2-3 chronic kidney disease (CKD). This study aimed to explore the efficacy of rosuvastatin in the female TRACK-D population.

Methods: This study was a gender-based analysis of 2,998 patients (1,044 females) enrolled in the TRACK-D study and were randomized to short-term (2 days before and 3 days after procedure) rosuvastatin therapy or standard of care. The primary outcome was the incidence of CIAKI and the secondary outcome was a composite of death, dialysis/hemofiltration or worsening heart failure at 30 days.

Results: CIAKI incidence was comparable between male and female patients in the overall study population $(2.5 \%$ vs. $3.4 \%, \mathrm{P}=0.165)$ and in the rosuvastatin group $(2.4 \%$ vs. $2.1 \%, \mathrm{P}=0.72)$, while it was higher in females than in males in the control group $(3.1 \%$ vs. $5.3 \%, \mathrm{P}=0.04)$. Female gender was an independent risk factor of CIAKI [odds ratio $(\mathrm{OR})=1.65$; $95 \%$ confidence interval $(\mathrm{CI}), 1.03-2.63 ; \mathrm{P}=0.036$ ]. Rosuvastatin treatment $v s$. control lowered CIAKI rate in females $[2.1 \%$ vs. $5.3 \%$; relative risk $(\mathrm{RR})=0.39$; 95\% CI, 0.19-0.77; number needed to treat $(\mathrm{NNT})=31$ ], particularly among those with CKD stage $2(1.2 \%$ vs. $4.1 \%, \mathrm{P}=0.011)$. Secondary outcome incidence was similar for females in the rosuvastatin and control groups $(3.7 \%$ vs. $4.9 \%, \mathrm{P}=0.37)$.
\end{abstract}

Conclusions: Compared to males, untreated females with diabetes mellitus and CKD had a higher risk of CIAKI, which can be reduced by short-term rosuvastatin treatment.

Keywords: Contrast medium; kidney injury; statin; female; diabetes; chronic kidney disease (CKD)

Submitted Dec 07, 2015. Accepted for publication Feb 29, 2016.

doi: $10.21037 /$ jtd.2016.03.26

View this article at: http://dx.doi.org/10.21037/jtd.2016.03.26

\section{Introduction}

Contrast-induced acute kidney injury (CIAKI), which is independently associated with longer hospital stay, hemodialysis if acute renal failure develops, heart failure and high in- and post-hospital mortality (1-4), has an overall incidence of $1-6 \%$ (5) that can climb up to $50 \%$ in individuals with diabetes mellitus and chronic kidney disease (CKD) $(6,7)$. Risk factors for CIAKI include older age, diabetes mellitus, decreased left ventricular ejection fraction, preexisting renal impairment, and a high volume 
of contrast medium $(7,8)$; with females being at greater risk than males $(9,10)$.

In the multicenter, randomized TRACK-D study, we reported that periprocedural use of rosuvastatin effectively reduced the risk of CIAKI in patients with diabetes and CKD undergoing coronary/peripheral arterial angiography and percutaneous intervention (11). The benefit of rosuvastatin therapy, regarding CIAKI, was consistently effective among various subgroups, including gender. Given that female is independently predicting CIAKI, detailed gender-based analysis is necessary to elucidate the efficacy of such strategy in female patients. This study investigated the efficacy of short-term rosuvastatin treatment for the prevention of CIAKI in female patients enrolled in the TRACK-D study.

\section{Methods}

\section{Study population}

The TRACK-D trial design has been previously described in detail (11). In brief, this investigator-initiated, prospective, randomized, controlled trial enrolled patients with type 2 diabetes and stage 2 or 3 CKD undergoing coronary/peripheral arterial diagnostic angiography, left ventriculography, or percutaneous coronary intervention (PCI) in 53 Chinese centers. Main exclusion criteria were hypersensitivity to contrast medium or statins, type 1 diabetes mellitus, ketoacidosis, lactic acidosis, stage 0 or 1 CKD, stage 4 or 5 CKD, acute ST-segment elevation myocardial infarction within the previous 4 weeks, class IV heart failure as defined by the New York Heart Association (NYHA) functional classification system, hemodynamic instability, administration of iodinated contrast medium during the 2 weeks before randomization, low-density lipoprotein cholesterol concentration $<1.82 \mathrm{mmol} / \mathrm{L}$, hepatic dysfunction, renal artery stenosis (unilateral $>70 \%$ or bilateral $>50 \%$ ). All patients provided written informed consent before enrollment, and the study was approved by the Ethics Committee of all participated centers.

\section{Study treatment}

Patients were randomized to treatment with either rosuvastatin (Crestor; Astra Zeneca, UK), $10 \mathrm{mg}$ every evening or blank control from 2 days before to 3 days after contrast medium administration. Statin therapy was resumed in both groups 3 days after contrast medium administration. Hydration therapy was administered at the physicians' discretion. The iso-osmolar, nonionic contrast medium iodixanol (Visipaque; GE Healthcare) was administered during all intervention procedures.

\section{Study outcomes and definitions}

The primary outcome was the development of CIAKI, defined as an increase in serum creatinine concentration $\geq 0.5 \mathrm{mg} / \mathrm{dL}(44.2 \mathrm{mmol} / \mathrm{L})$ or $\geq 25 \%$ above baseline at $72 \mathrm{~h}$ after exposure to the contrast medium. Secondary outcome was a composite of adverse clinical events at 30 days, including all-cause death, dialysis/hemofiltration or worsening heart failure, defined as a deteriorated NYHA functional class (class change $\geq 1$ ). The estimated glomerular filtration rate (eGFR) was calculated from serum creatinine ( $\mathrm{sCr}$ ) concentrations by using the modified glomerular filtration rate estimating equation for Chinese patients with CKD (12): eGFR $\left(\mathrm{mL} / \mathrm{min} / 1.73 \mathrm{~m}^{2}\right)=175 \times(\mathrm{sCr})^{-1.234} \times$ $(\text { age })^{-0.179}(0.79$ if female).

\section{Statistical analysis}

Analysis was performed with SPSS 19.0 software by the Chinese Cardiovascular Research Foundation. Comparisons among normally distributed continuous variables, expressed as mean \pm standard deviation, were performed using Student $t$-tests; non-normally distributed continuous variables, presented as medians and interquartile ranges, were analyzed using Wilcoxon rank-sum tests. The Chisquare or Fisher exact test was used for categorical data, expressed as percentages. Logistic regression analysis was used to calculate odds ratios (OR) for the comparison of CIAKI rates between groups. All $\mathrm{P}$ values were 2 -tailed, and statistical significance was defined by a $\mathrm{P}$ value 0.05 .

\section{Results}

\section{Patients}

Between December 2008 and October 2011, 2,998 patients were enrolled at 53 centers in China: 1,044 (34.8\%) patients were female and 1,954 (65.2\%) were male. For female patients, $535(51.2 \%)$ were allocated to the rosuvastatin group and $509(48.8 \%)$ to the control group (Figure 1). Baseline characteristics of female and male patients are demonstrated in Table 1. Compared with male patients, female patients were older, had longer course of diabetes, 


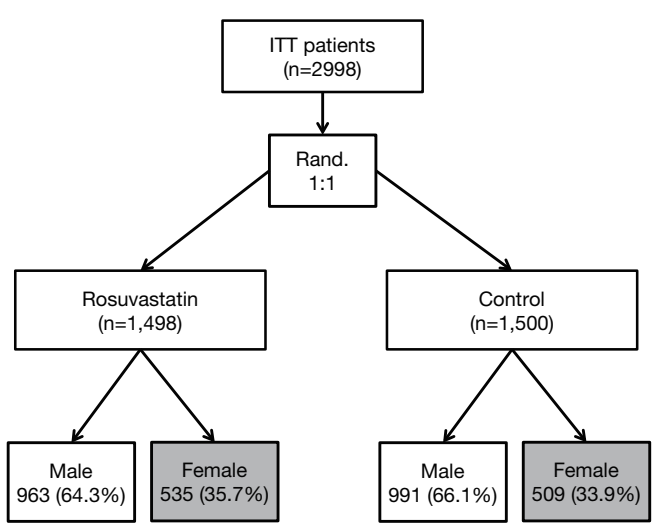

Figure 1 Study flowchart. ITT, intention-to-treat.

higher proportion of hypertension, anemia and higher serum total and low-density lipoprotein cholesterol levels (all $\mathrm{P}<0.01)$. Hydration was performed less frequently in female patients ( $39.9 \%$ vs. $46.0 \%, \mathrm{P}<0.01)$. The level of $\mathrm{sCr}$ was lower in females than males $(\mathrm{P}<0.01)$.

\section{Clinical outcomes of female and male patients}

Incidence of CIAKI was comparable between male and female patients in the overall population $(2.5 \%$ vs. $3.4 \%, \mathrm{P}=0.165)$ and in the rosuvastatin group $(2.4 \%$ vs. $2.1 \%, \mathrm{P}=0.72)$, but significantly higher for female patients in the control group (3.1\% vs. 5.3\%, $\mathrm{P}=0.04$ ) (Figure 2). After adjusting for confounders, female gender was still an independent risk factor of CIAKI $[\mathrm{OR}=1.65 ; 95 \%$ confidence interval (CI), 1.03-2.63; $\mathrm{P}=0.036]$. The interaction $\mathrm{P}$ value between gender and rosuvastatin treatment was 0.124 .

\section{Baseline characteristics and clinical outcomes of female patients}

Baseline clinical characteristics, intervention results and laboratory outcomes of female patients were comparable between rosuvastatin and control group (Tables 2,3).

At 30-day follow-up, the incidence of CIAKI was significantly lower in the rosuvastatin group compared to which in the control group for female patients [2.1\% vs. $5.3 \%$; relative risk $(\mathrm{RR})=0.39,95 \% \mathrm{CI}, 0.19-0.77$; number needed to treat $(\mathrm{NNT})=31$ ] (Figure 3). Regarding the different CKD stage subsets, short-term rosuvastatin treatment resulted in a significant $70 \% \mathrm{RR}$ reduction of CIAKI in female patients with CKD stage $2(1.2 \%$ vs. $4.1 \% ; \mathrm{RR}=0.30 ; 95 \% \mathrm{CI}, 0.11-0.80 ; \mathrm{NNT}=35)$ and a
Table 1 Comparison of baseline characteristics and laboratory outcomes between male and female patients in the overall TRACK-D study patient population

\begin{tabular}{|c|c|c|c|}
\hline Variables & $\begin{array}{c}\text { Male } \\
(n=1,954)\end{array}$ & $\begin{array}{c}\text { Female } \\
(n=1,044)\end{array}$ & $P$ value \\
\hline Age, years & $60.02 \pm 8.91$ & $64.10 \pm 7.41$ & $<0.01$ \\
\hline Body mass index, $\mathrm{kg} / \mathrm{m}^{2}$ & $25.59 \pm 2.83$ & $25.52 \pm 3.21$ & 0.52 \\
\hline Anemia & $143(7.3)$ & $102(9.8)$ & 0.02 \\
\hline Diabetes history, years & & & $<0.01$ \\
\hline$<5$ & $1,140(58.3)$ & $531(50.9)$ & \\
\hline $5-10$ & $366(18.7)$ & 201 (19.3) & \\
\hline$>10$ & 448 (22.9) & 312 (29.9) & \\
\hline Hypertension & $1,356(69.4)$ & $800(76.6)$ & $<0.01$ \\
\hline Congestive heart failure & $290(14.8)$ & $175(16.8)$ & 0.17 \\
\hline Peripheral vascular disease & $63(3.2)$ & $19(1.8)$ & 0.03 \\
\hline History of liver disease & $18(0.9)$ & $7(0.7)$ & 0.53 \\
\hline NYHA functional class & & & 0.33 \\
\hline I & $1,664(85.2)$ & $869(83.2)$ & \\
\hline II & $255(13.1)$ & $151(14.5)$ & \\
\hline III & $35(1.8)$ & $24(2.3)$ & \\
\hline Hydration treatment & $898(46.0)$ & 417 (39.9) & $<0.01$ \\
\hline \multicolumn{4}{|l|}{ Serum creatinine, $\mu \mathrm{mol} / \mathrm{L}$} \\
\hline Baseline & $98.44 \pm 20.04$ & $82.73 \pm 25.58$ & $<0.01$ \\
\hline $\begin{array}{l}\text { Maximal values after } \\
\text { procedure }\end{array}$ & $100.69 \pm 24.03$ & $85.55 \pm 30.06$ & $<0.01$ \\
\hline \multicolumn{4}{|l|}{ eGFR, $\mathrm{mL} /\left(\min \cdot 1.73 \mathrm{~m}^{2}\right)$} \\
\hline Baseline & $74.75 \pm 14.15$ & $73.44 \pm 16.75$ & 0.02 \\
\hline $\begin{array}{l}\text { Minimal values after } \\
\text { procedure }\end{array}$ & $75.67 \pm 17.17$ & $74.45 \pm 21.35$ & 0.09 \\
\hline \multicolumn{4}{|l|}{ Total cholesterol, mg/L } \\
\hline Baseline & $4.41 \pm 1.12$ & $4.92 \pm 1.20$ & $<0.01$ \\
\hline Follow-up & $4.16 \pm 1.05$ & $4.60 \pm 1.10$ & $<0.01$ \\
\hline Absolute change & $-0.25 \pm 0.85$ & $0.31 \pm 0.94$ & 0.09 \\
\hline \multicolumn{4}{|l|}{ LDL-C, mg/L } \\
\hline Baseline & $2.45 \pm 0.78$ & $2.69 \pm 0.82$ & $<0.01$ \\
\hline Follow-up & $2.28 \pm 0.69$ & $2.48 \pm 0.70$ & $<0.01$ \\
\hline Absolute change & $-0.18 \pm 0.61$ & $-0.20 \pm 0.64$ & 0.33 \\
\hline \multicolumn{4}{|l|}{ hsCRP, mg/L } \\
\hline Baseline & $1.23 \pm 2.75$ & $1.25 \pm 5.02$ & 0.96 \\
\hline Follow-up & $1.08 \pm 2.48$ & $1.09 \pm 1.93$ & 0.25 \\
\hline Absolute change & $-0.15 \pm 2.72$ & $-0.16 \pm 2.36$ & 0.40 \\
\hline Contrast volume, $\mathrm{mL}$ & 120 [100-200] & 100 [100-200] & ] $<0.01$ \\
\hline \multicolumn{4}{|c|}{$\begin{array}{l}\text { Data are presented as } \mathrm{n}(\%) \text {, mean } \pm \text { standard deviation, or } \\
\text { median [interquartile range]. NYHA, New York Heart Association; } \\
\text { eGFR, estimated glomerular filtration rate; LDL-C, low-density }\end{array}$} \\
\hline
\end{tabular}




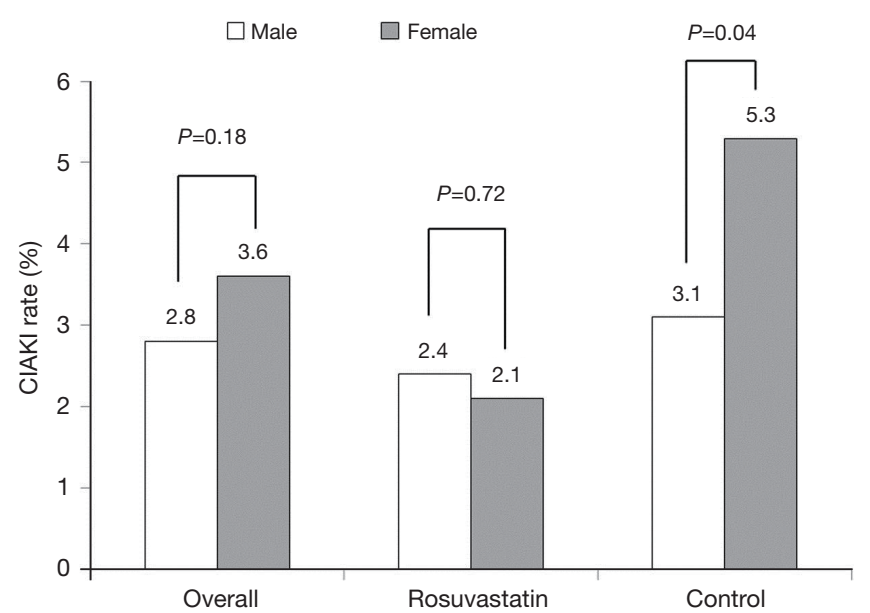

Figure 2 CIAKI rate of male $v s$. female patients in different treatment arms. CIAKI, contrast induced acute kidney injury.

non-significant $60 \% \mathrm{RR}$ reduction in those with $\mathrm{CKD}$ stage 3 (3.3\% vs. $8.4 \%$; RR $=0.40 ; 95 \%$ CI, $0.11-1.48$; $\mathrm{NNT}=20)$ (Figure 3). Clinical adverse events including allcause deaths, dialysis and worsening heart failure at 30-day follow-up after contrast medium administration were not different between rosuvastatin and control group (3.7\% vs. $4.9 \%$;R $=0.76$; 95\% CI, 0.43-1.35) (Table 4).

\section{Discussion}

TRACK-D was a prospective, randomized, controlled, multicenter clinical trial performed in China aimed at assessing the efficacy of short-term rosuvastatin to prevent CIAKI in a larger population of diabetic patients with mild to moderate CKD who were undergoing coronary or peripheral arterial diagnostic angiography or percutaneous intervention (11). This gender-based analysis of TRACK-D population showed that females with diabetes and CKD were at higher risk of CIAKI compared to their male counterparts and were benefit from short-term rosuvastatin treatment during peri-operative period of angiography or percutaneous intervention.

Previous studies have suggested that diabetes mellitus, $\mathrm{CKD}$, advanced age, severe heart failure and a high volume of contrast medium were independent predictors of CIAKI (13). Other studies have demonstrated that female gender, with or without $\mathrm{CKD}$, is an independent predictor of CIAKI development after PCI procedure. Compared with men, women have increased cardiovascular mortality, especially after menopause (14). Specifically, in-hospital mortality after
Table 2 Comparison of baseline characteristics between rosuvastatin and control groups in females

\begin{tabular}{|c|c|c|c|}
\hline Variables & $\begin{array}{l}\text { Rosuvastatin } \\
\text { group } \\
(n=535)\end{array}$ & $\begin{array}{l}\text { Control group } \\
\qquad(n=509)\end{array}$ & $P$ value \\
\hline Age, years & $64.25 \pm 7.51$ & $63.99 \pm 7.28$ & 0.65 \\
\hline $\begin{array}{l}\text { Body mass index, } \\
\mathrm{kg} / \mathrm{m}^{2}\end{array}$ & $25.41 \pm 3.17$ & $67.88 \pm 10.29$ & 0.13 \\
\hline Anemia & $38(9.1)$ & $41(8.1)$ & 0.57 \\
\hline Diabetes history, years & & & 0.89 \\
\hline$<5$ & $276(51.6)$ & $255(50.1)$ & \\
\hline $5-10$ & $102(19.1)$ & $99(19.4)$ & \\
\hline$>10$ & $157(29.3)$ & $155(30.5)$ & \\
\hline Hypertension & $418(78.1)$ & $382(75.0)$ & 0.24 \\
\hline Hypertriglyceridemia & $42(7.9)$ & $48(9.4)$ & 0.39 \\
\hline $\begin{array}{l}\text { Congestive heart } \\
\text { failure }\end{array}$ & $87(16.3)$ & $88(17.3)$ & 0.66 \\
\hline $\begin{array}{l}\text { Peripheral vascular } \\
\text { disease }\end{array}$ & $13(2.4)$ & $6(1.2)$ & 0.17 \\
\hline $\begin{array}{l}\text { History of liver } \\
\text { disease }\end{array}$ & $4(0.7)$ & $3(0.6)$ & 1.00 \\
\hline $\begin{array}{l}\text { Prior myocardial } \\
\text { infarction }\end{array}$ & $72(13.5)$ & 57 (11.2) & 0.30 \\
\hline NYHA functional class & & & 0.89 \\
\hline I & $276(51.6)$ & $255(50.1)$ & \\
\hline II & $102(19.1)$ & $99(19.4)$ & \\
\hline III & $157(29.3)$ & $155(30.5)$ & \\
\hline Hydration treatment & $216(40.4)$ & $201(39.5)$ & 0.77 \\
\hline CKD classification & & & 0.85 \\
\hline Stage 2 & $411 / 501(82.0)$ & $391 / 474(82.5)$ & \\
\hline Stage 3 & 90/501 (18.0) & $83 / 474(17.5)$ & \\
\hline
\end{tabular}

Data are presented as $n(\%)$, mean \pm standard deviation. NYHA, New York Heart Association; CKD, chronic kidney disease.

coronary angiography is higher in women $(15,16)$, although in these cohorts, women were older and had a greater burden of comorbidity than men (17-19). CIAKI may be a factor in the relatively detrimental hospital course observed in women, although the reason for the higher incidence of CIAKI in women is unknown. Gender-specific responses to renal stimuli by contrast medium and the influence of ovarian hormones are possible explanations (15). Furthermore, older women may have lower intrarenal medullary oxygenation (20), which 
Table 3 Comparison of intervention and laboratory characteristics between rosuvastatin and control groups in females

\begin{tabular}{|c|c|c|c|}
\hline Variables & $\begin{array}{l}\text { Rosuvastatin } \\
\text { group }(n=535)\end{array}$ & $\begin{array}{l}\text { Control group } \\
\qquad(n=509)\end{array}$ & $P$ value \\
\hline $\begin{array}{l}\text { Peripheral vascular } \\
\text { angiography }\end{array}$ & $68(12.7)$ & $72(14.1)$ & 0.79 \\
\hline \multicolumn{3}{|c|}{ Coronary diagnostic angiography } & 0.20 \\
\hline None & $83(15.5)$ & $85(16.7)$ & \\
\hline Single-vessel & $117(21.9)$ & $132(25.9)$ & \\
\hline Multi-vessel & $335(62.6)$ & $292(57.4)$ & \\
\hline $\begin{array}{l}\text { Percutaneous } \\
\text { coronary intervention }\end{array}$ & $259(48.4)$ & $226(44.4)$ & 0.21 \\
\hline $\begin{array}{l}\text { Percutaneous } \\
\text { peripheral intervention }\end{array}$ & $3(0.6)$ & $5(1.0)$ & 0.50 \\
\hline \multicolumn{4}{|c|}{ Serum creatinine, $\mu \mathrm{mol} / \mathrm{L}$} \\
\hline Baseline & $84.44 \pm 22.24$ & $84.63 \pm 21.50$ & 0.88 \\
\hline $\begin{array}{l}\text { Maximal values after } \\
\text { procedure }\end{array}$ & $84.76 \pm 24.42$ & $86.38 \pm 35.03$ & 0.39 \\
\hline \multicolumn{4}{|l|}{ eGFR, $\mathrm{mL} /\left(\min \cdot 1.73 \mathrm{~m}^{2}\right)$} \\
\hline Baseline & $73.35 \pm 15.74$ & $73.54 \pm 17.77$ & 0.86 \\
\hline $\begin{array}{l}\text { Minimal values after } \\
\text { procedure }\end{array}$ & $74.49 \pm 21.99$ & $74.39 \pm 20.67$ & 0.94 \\
\hline \multicolumn{4}{|c|}{ Urinary protein to creatinine excretion ratio } \\
\hline Baseline & $0.39 \pm 2.61$ & $0.13 \pm 0.87$ & 0.08 \\
\hline $\begin{array}{l}\text { Maximal values after } \\
\text { procedure }\end{array}$ & $0.29 \pm 2.02$ & $0.16 \pm 1.05$ & 0.35 \\
\hline Contrast volume, mL & $100[100-200]$ & 100 [100-200] & 0.14 \\
\hline \multicolumn{4}{|l|}{ Total cholesterol, mg/L } \\
\hline Baseline & $4.93 \pm 1.21$ & $4.92 \pm 1.19$ & 0.97 \\
\hline Follow-up & $4.19 \pm 0.97$ & $5.01 \pm 1.08$ & $<0.01$ \\
\hline Absolute change & $-0.71 \pm 0.79$ & $0.10 \pm 0.62$ & $<0.01$ \\
\hline \multicolumn{4}{|l|}{ LDL-C, mg/L } \\
\hline Baseline & $2.71 \pm 0.88$ & $2.68 \pm 0.75$ & 0.62 \\
\hline Follow-up & $2.22 \pm 0.66$ & $2.74 \pm 0.65$ & $<0.01$ \\
\hline Absolute change & $-0.45 \pm 0.62$ & $0.04 \pm 0.56$ & $<0.01$ \\
\hline \multicolumn{4}{|l|}{ hsCRP, mg/L } \\
\hline Baseline & $1.23 \pm 2.75$ & $1.15 \pm 5.02$ & 0.68 \\
\hline Follow-up & $1.08 \pm 2.48$ & $1.82 \pm 5.93$ & 0.01 \\
\hline Absolute change & $-0.13 \pm 2.72$ & $0.25 \pm 2.36$ & $<0.01$ \\
\hline
\end{tabular}

Data are presented as $\mathrm{n}(\%)$, mean \pm standard deviation, or median (interquartile range). eGFR, estimated glomerular filtration rate; LDL-C, low-density lipoprotein cholesterol; hsCRP, hypersensitive $\mathrm{C}$ reactive protein.

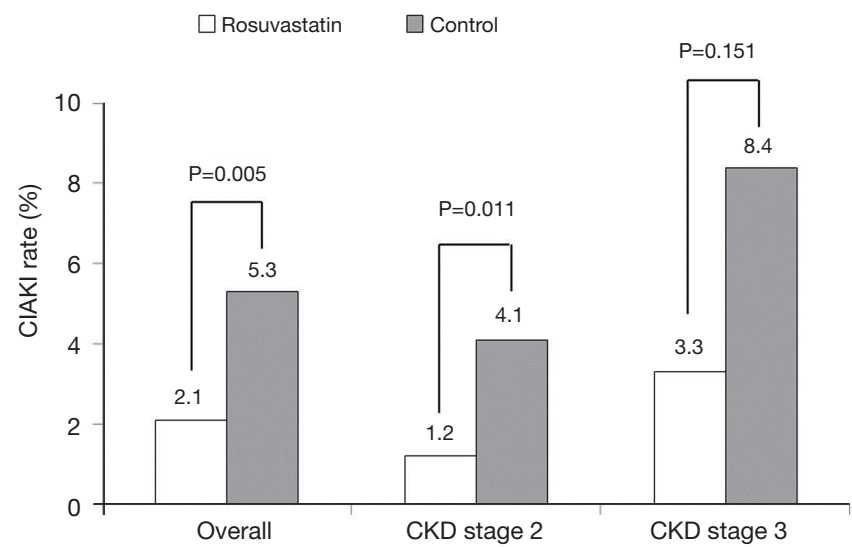

Figure 3 CIAKI rate of female patients received rosuvastatin or blank control treatment. CIAKI, contrast induced acute kidney injury; CKD, chronic kidney disease.

Table 4 Thirty-day follow-up after contrast medium administration in female patients

\begin{tabular}{|c|c|c|c|}
\hline Outcomes & $\begin{array}{c}\text { Rosuvastatin group } \\
\qquad(\mathrm{n}=535)\end{array}$ & $\begin{array}{l}\text { Control group } \\
\quad(n=509)\end{array}$ & $\begin{array}{c}\mathrm{RR} \\
(95 \% \mathrm{Cl})\end{array}$ \\
\hline $\begin{array}{l}\text { All-cause } \\
\text { death }\end{array}$ & $1(0.2)$ & $3(0.6)$ & $\begin{array}{c}0.32 \\
(0.03-3.04)\end{array}$ \\
\hline $\begin{array}{l}\text { Dialysis/ } \\
\text { hemofiltration }\end{array}$ & $0(0.0)$ & $1(0.2)$ & $N / A$ \\
\hline $\begin{array}{l}\text { Worsening } \\
\text { heart failure }\end{array}$ & 19 (3.6) & $21(4.1)$ & $\begin{array}{c}0.86 \\
(0.47-1.58)\end{array}$ \\
\hline Composite & $20(3.7)$ & $25(4.9)$ & $\begin{array}{c}0.76 \\
(0.43-1.35)\end{array}$ \\
\hline
\end{tabular}

Data are presented as $\mathrm{n}(\%)$. RR, relative risk; $\mathrm{Cl}$, confidence interval; N/A, not applicable.

may be linked to lower intrarenal medullary prostaglandin production (21), a potential risk factor for increased susceptibility to CIAKI. The increased risk of CIAKI in women may be also related to the contrast medium dose, namely a higher ratio of contrast volume to body surface area.

In our study, women were older, more likely anemic and hypertensive, and were treated by hydration less frequently than men, which might be the explanations of the higher incidence of CIAKI in women. However, the increased risk of CIAKI in women persisted after multivariable adjustment for these confounders. Those findings highlight the need 
to re-assess the efficacy and safety of rosuvastatin in female patients and to make evidence-based decisions in women with higher risk of CIAKI. In the present study, female patients not treated with rosuvastatin had a significantly higher incidence of CIAKI compared with their male counterparts, whereas the CIAKI rates were comparable between male and female patients treated with perioperative rosuvastatin. The above findings indicated that the effects of rosuvastatin appear to be more pronounced in females. Given few medications have been proven effective as so far, our findings provided a promising and feasible strategy for the management of CIAKI in female patients with diabetes and CKD, who were at high risk of CIAKI. That is valuable to enhance clinical performance in such patient cohort.

Further analysis showed that the beneficial effects of rosuvastatin treatment was more obvious in females with stage $2 \mathrm{CKD}$ but was not significant in those with stage 3 CKD. However, as we shown in the results, stage 3 CKD patients had a comparable RR reduction and even small NNT (20 vs. 31) from rosuvastatin treatment compared with that of stage 2 CKD patients. The most possible explanation of it was the small sample size of stage $3 \mathrm{CKD}$ patients (90 in rosuvastatin group and 83 in control group, respectively). Therefore, it was reasonable to suppose that rosuvastatin is efficacy in both stage 2 and 3 CKD patients. On the other hand, only $10 \mathrm{mg}$ per day rosuvastatin was used in the present study, which was lower than routine dosage reported in studies launched in Western countries. Thus, another possible reason was that the treatment intensiveness might not be enough to overcome the injury caused by worse baseline diseases (CKD stage 3 ). The validation of above hypothesis needs further confirmation by randomized trial with large sample size.

The mechanism of rosuvastatin in CI-AKI prevention for female patients remains unknown. In the present study, hsCRP level was lower in rosuvastatin treated females as compared to females allocated in the control group, which was consistent to the results from overall TRACK-D population. An increased hsCRP level is known to be associated with CIAKI development. Therefore, rosuvastatin, which also has anti-inflammatory activity, might reduce CIAKI risk by lowering hsCRP level.

Limitations: Data presented in this study were derived from a prespecified but post-randomized analysis. Although baseline characteristics were well matched between the two arms, results should be interpreted with caution due to potential bias caused by underpowered sample size and non- stratified randomization. Moreover, the beneficial effects of rosuvastatin treatment was only significant in patients with CKD stage 2, which might be also caused by underpowered sample size because the difference for CKD stage 3 did not reach statistical significance. Findings of this study warrant confirmation in a randomized clinical trial with larger sample size.

\section{Conclusions}

Female patients with DM and CKD undergoing coronary/ peripheral angiography or interventions are at higher risk of CIAKI compared to male patients. Short-term rosuvastatin treatment is effective in reducing 30-day CIAKI rate for female patients.

\section{Acknowledgements}

Funding: The study was supported by grants from the Key Technologies R\&D project of Liaoning Province (No. 2013225089) and Key Project of the National 12th Five-Year Research Program of China (No. 2012ZX09303016-002).

\section{Footnote}

Conflicts of Interest: The authors have no conflicts of interest to declare.

\section{References}

1. Brown JR, DeVries JT, Piper WD, et al. Serious renal dysfunction after percutaneous coronary interventions can be predicted. Am Heart J 2008;155:260-6.

2. Maioli M, Toso A, Gallopin M, et al. Preprocedural score for risk of contrast-induced nephropathy in elective coronary angiography and intervention. J Cardiovasc Med (Hagerstown) 2010;11:444-9.

3. Mehran R, Aymong ED, Nikolsky E, et al. A simple risk score for prediction of contrast-induced nephropathy after percutaneous coronary intervention: development and initial validation. J Am Coll Cardiol 2004;44:1393-9.

4. Watabe H, Sato A, Hoshi T, et al. Association of contrastinduced acute kidney injury with long-term cardiovascular events in acute coronary syndrome patients with chronic kidney disease undergoing emergent percutaneous coronary intervention. Int J Cardiol 2014;174:57-63.

5. Bartholomew BA, Harjai KJ, Dukkipati S, et al. Impact of nephropathy after percutaneous coronary intervention 
and a method for risk stratification. Am J Cardiol 2004;93:1515-9.

6. Chen SL, Zhang J, Yei F, et al. Clinical outcomes of contrastinduced nephropathy in patients undergoing percutaneous coronary intervention: a prospective, multicenter, randomized study to analyze the effect of hydration and acetylcysteine. Int J Cardiol 2008;126:407-13.

7. McCullough PA, Adam A, Becker CR, et al. Risk prediction of contrast-induced nephropathy. Am J Cardiol 2006;98:27K-36K.

8. McCullough PA. Acute kidney injury with iodinated contrast. Crit Care Med 2008;36:S204-11.

9. Patti G, Nusca A, Chello M, et al. Usefulness of statin pretreatment to prevent contrast-induced nephropathy and to improve long-term outcome in patients undergoing percutaneous coronary intervention. Am J Cardiol 2008;101:279-85.

10. Lucreziotti S, Centola M, Salerno-Uriarte D, et al. Female gender and contrast-induced nephropathy in primary percutaneous intervention for ST-segment elevation myocardial infarction. Int J Cardiol 2014;174:37-42.

11. Han Y, Zhu G, Han L, et al. Short-term rosuvastatin therapy for prevention of contrast-induced acute kidney injury in patients with diabetes and chronic kidney disease. J Am Coll Cardiol 2014;63:62-70.

12. Ma YC, Zuo L, Chen JH, et al. Modified glomerular filtration rate estimating equation for Chinese patients with chronic kidney disease. J Am Soc Nephrol 2006;17:2937-44.

13. Andò G, de Gregorio C, Morabito G, et al. Renal function-adjusted contrast volume redefines the baseline estimation of contrast-induced acute kidney injury risk in patients undergoing primary percutaneous coronary intervention. Circ Cardiovasc Interv 2014;7:465-72.

Cite this article as: Li J, Li Y, Xu B, Jia G, Guo T, Wang D, $\mathrm{Xu}$ K, Deng J, Han Y. Short-term rosuvastatin therapy prevents contrast-induced acute kidney injury in female patients with diabetes and chronic kidney disease: a subgroup analysis of the TRACK-D study. J Thorac Dis 2016;8(5):1000-1006. doi: $10.21037 /$ jtd.2016.03.26
14. Rezaeian S, Moghimbeigi A, Esmailnasab N. Gender differences in risk factors of congenital hypothyroidism: an interaction hypothesis examination. Int J Endocrinol Metab 2014;12:e13946.

15. Iakovou I, Dangas G, Mehran R, et al. Impact of gender on the incidence and outcome of contrast-induced nephropathy after percutaneous coronary intervention. J Invasive Cardiol 2003;15:18-22.

16. Park K, Chung WY, Seo JB, et al. The prevention of contrast induced nephropathy by sarpogrelate in patients with chronic kidney disease: a study protocol for a prospective randomized controlled clinical trial. Trials 2010;11:122.

17. Kiski D, Stepper W, Breithardt G, et al. Impact of female gender on frequency of contrast medium-induced nephropathy: post hoc analysis of dialysis versus diuresis trial. J Womens Health (Larchmt) 2010;19:1363-8.

18. Mikkelsen AP, Lindhardsen J, Lip GY, et al. Female sex as a risk factor for stroke in atrial fibrillation: a nationwide cohort study. J Thromb Haemost 2012;10:1745-51.

19. Mueller C, Buerkle G, Perruchoud AP, et al. Female sex and risk of contrast nephropathy after percutaneous coronary intervention. Can J Cardiol 2004;20:505-9.

20. Prasad PV, Epstein FH. Changes in renal medullary pO2 during water diuresis as evaluated by blood oxygenation level-dependent magnetic resonance imaging: effects of aging and cyclooxygenase inhibition. Kidney Int 1999;55:294-8.

21. Gottlieb DJ, Stone PJ, Sparrow D, et al. Urinary desmosine excretion in smokers with and without rapid decline of lung function: the Normative Aging Study. Am J Respir Crit Care Med 1996;154:1290-5. 